\title{
EFFECT OF DIFFERENT CRYOPROTECTANTS ON THE POST-THAW SPERM CHARACTERISTICS AND IN VIVO FERTILITY OF BUFFALO (Bubalus bubalis) BULL SEMEN
}

\author{
Essam A. Almadaly ${ }^{1 *}$, Fady S. Tawfik², Ismail I. El-Kon¹, Bassiouni A. Heleil'1, \\ El-Sayed M. Fattouh ${ }^{1}$
}

${ }^{1}$ Department of Theriogenology, Faculty of Veterinary Medicine, Kafrelsheikh University, El-Geish Street, 33516 Kafrelsheikh, Egypt, ${ }^{2}$ Artificial Insemination Center, Veterinary Medicine Directorate, Ministry of Agriculture, Al-Gharbia, Egypt

*Corresponding author, E-mail: dr_essam_2005@yahoo.com; essam.mostafa@vet.kfs.edu.eg

\begin{abstract}
This study aimed to investigate the effect of different cryoprotectants, glycerol (GLY) or ethylene glycol (EG) or dimethyl sulfoxide (DMSO) on sperm characteristics, and in vivo fertility of frozen-thawed buffalo-bull semen. A total of 85 ejaculates collected by artificial vagina from buffalo-bulls of proven fertility were used in this study. The collected ejaculates were examined for volume, motility, viability, morphology, and sperm cell concentration. The qualifying ejaculates ( $\geq 3$ mass motion, $>70 \%$ progressive motility and viability, $<15 \%$ abnormal morphology and $>1 \times 10^{9}$ sperm cells $/ \mathrm{mL}$ ) were pooled and diluted with Tris-based diluent containing either $7 \%$ GLY or $5 \%$ EG or 5\% DMSO. After $4 \mathrm{~h}$ equilibration time, the diluted semen was loaded in $0.5 \mathrm{~mL}$ straws, labeled, sealed and frozen stored until analysis. Frozen straws were thawed and evaluated for progressive motility, viability, hypo-osmotic swelling test (HOST), acrosomal membrane integrity, and acrosome reaction (AR) in response to calcium ionophore A23187. Moreover, in vivo fertility was calculated after artificial insemination (Al) of 75 buffalo-cows (25 female/cryoprotectant) treated with double doses of prostaglandin $F_{2 \alpha}\left(P F_{2 \alpha}\right) 11$ days interval. The proportions of progressive motility, viability and intact-acrosome were higher $(p<0.05)$ in extender containing 7\% GLY compared to 5\% EG and 5\% DMSO. The proportion of intact-plasma membrane was comparable $(p \geq 0.05)$ between GLY and EG but higher than that of DMSO. A time-dependent increase in the $\% A R$ and $\%$ relative $A R$ was recorded in the three cryoprotectants with clear significant $(p<0.01)$ difference among them at 30 and 60 min incubation, respectively. Moreover, GLY yielded higher pregnancy rate (52\%) than EG (32\%) and DMSO (16\%). In conclusion, GLY is recommended for preservation of buffalo-bull semen in order to maintain sperm plasma membrane integrity and improve in vivo fertility of frozen-thawed buffalo-bull semen.
\end{abstract}

Key words: buffalo-bull; frozen-thawed semen; cryoprotectant; estrus synchronization; In vivo fertility.

\section{Introduction}

Received: January 2019

Accepted for publication: February 2019
Buffalo (Bubalus bubalis) is the most important and popular livestock animal for milk 
production in Egypt. It was introduced to Egypt from India, Iran and Iraq around the middle of the $7^{\text {th }}$ century. Its lactation season ranged from 210-280 day with annual average of $915 \mathrm{~kg}$ milk/animal. The total population of buffaloes in Egypt was decrease from 4.16 million in 2012 to 3.64 million in 2016 (1) with decline of approximately $11 \%$ within four years, most of them reared in small herds (1-3 animals). Despite it is the best milk, meat and leather producing animal in our country but it has not received sufficient consideration regarding the improvement of its breeding strategies.

Improvement of livestock production can be achieved using one of the assisted reproductive technologies such as artificial insemination (AI) (2) which is an essential tool for the quick dispersion of valuable germplasm and the feasible method to improve the genetic quality of farm animals (3). Cryopreservation is an essential method for conservation of germ cells and is suitable for the proper genetic management (4). Semen quality and fertility is clearly reduced by freezing-thawing damage compared with fresh semen and it can be compensated by the insemination of larger number of sperm cells. Generally, $40-50 \%$ of sperm cells die after cryopreservation even with optimized methodology (5) due to an inevitable chemical, osmotic, thermal, and mechanical stresses which lead to lower post-thaw motility and viability (6). Intracellular ice crystallization is implicated in this inevitable damage of spermatozoa during cryopreservation (7). Moreover, buffalo-bull spermatozoa are more vulnerable to freezing-thawing damage compared with other mammalian species (8).

The fertility rate of frozen-thawed buffalobull spermatozoa is ranged from $33 \%$ (9) to $45 \%$ (10). Sudden cooling of diluted semen from $30{ }^{\circ} \mathrm{C}$ toward $0{ }^{\circ} \mathrm{C}$ result in a lethal stress called cold shock in some of the sperm cells which was proportional with the cooling rate, the temperature interval and range (11). This sharp variation in temperature induces damage in sperm cell membranes. It is possible that these effects are related to phase change in lipids and altered functional state of membranes (6).
The composition of semen extender containing proper cryoprotectants is critical for successful semen cryopreservation (12) where the cryoprotectant minimize the intracellular ice crystals formation and/or damage. The penetrating cryoprotectants such as glycerol (GLY), ethylene glycol (EG) and dimethyl sulfoxide (DMSO) have the ability to pass through the sperm plasma membrane. Accordingly, it acts both intra and extra-cellular, rearrange the membrane proteins, reduce intracellular ice crystals formation and thus, protect sperm cells from freeze-thaw damage (13).

Addition of penetrating cryoprotectants to sperm cell suspension, the cells first shrink due to water efflux then swell as the cryoprotectant get intracellular with water to maintain chemical potential. During removal of cryoprotectant the cell will initially swell due to water influx and then return to isosmotic size due to efflux of cryoprotectant with water. This osmotic stress adversely affects sperm motility, viability and function (14).

Conventionally, GLY is used at concentration ranged from 5 to $8 \%$ to cryopreserve bovine sperm. However, it has both osmotic and toxic effects on the plasma membrane and metabolism of frozen-thawed semen with subsequent reduced motility and fertility (12). Also, higher concentration of GLY may lead to cell death (15). Recently, the high membrane permeability of EG was shown to reduce the plasma membrane damage of bovine sperm compared with GLY (16). Thus, apparently EG has less detrimental effect on viability and motility and offer protective effect to sperm acrosome than GLY (17). Nowadays, biotechnology of cryoprotectants play substantial role in improving the quality of frozen-thawed semen. Incorporation of efficient and less toxic cryoprotectant within semen extender can make a substantial impact in improving the quality of frozen-thawed buffalo-bull spermatozoa. Therefore, the present study aimed to investigate the effect of different cryoprotectants (GLY, EG and DMSO) on sperm characteristics and in vivo fertility of frozen-thawed buffalo-bull semen. 


\section{Materials and methods}

Animals

The present study was carried out at Mehalet-Mousa Research Station, Kafrelsheikh, Egypt. Five healthy Egyptian buffalo bulls (56 years-old) of proven fertility, acceptable libido and of good semen quality were used for semen collection. Seventy five Egyptian buffalo-cows (4-5 years-old) having history of normal parturition was used for in vivo fertility experiment. All animals were kept indoors all over the year and fed on ration that met both maintenance and production requirements. Buffalo-cows were fed on concentrates plus corn silage and straw in summer and concentrates plus green clover and straw in winter.

\section{Chemicals, media and reagents}

Unless otherwise stated, all chemicals used were of high purity and procured from SigmaAldrich Chemical Company (St. Louis, MO, USA). Freshly prepared Tris-based extender consists of $3.028 \mathrm{~g}$ Tris, $1.678 \mathrm{~g}$ citric acid and $1.0 \mathrm{~g}$ fructose, $20 \%$ (v/v) egg yolk, $1000 \mathrm{IU} / \mathrm{mL}$ penicillin $\mathrm{G}$ sodium, $1 \mathrm{mg} / \mathrm{mL}$ streptomycin sulfate and the same extender containing either $7 \%$ GLY (Sigma-Aldrich, USA) or 5\% EG (SDFCL, India) or 5\% DMSO (Fluka, Germany) was used for semen dilution and freezing (5). Saline medium consists of $142 \mathrm{mM} \mathrm{NaCl}$, $2.5 \mathrm{mM} \mathrm{KOH}, 10 \mathrm{mM}$ glucose and $20 \mathrm{mM}$ Hepes and adjusted to $\mathrm{pH} 7.55$ at $25^{\circ} \mathrm{C}$ with $\mathrm{NaOH}$ (18) was used for dilution and incubation of spermatozoa. Saline medium containing $275 \mathrm{mM}$ sucrose in place of $\mathrm{NaCl}$ was used for washing spermatozoa and designated as sucrose medium (18). Both media contained $0.1 \%$ (w/v) polyvinyl alcohol (PVA, molecular weight 30,000-70,000) and $0.1 \%(\mathrm{w} / \mathrm{v})$ polyethylene glycol (PEG). A fixative used was $2 \%$ Glutaraldehyde in $0.165 \mathrm{M}$ of sodium cacodylate buffer, adjusted to $\mathrm{pH} 7.3$ at $25{ }^{\circ} \mathrm{C}$. Sperm counting medium [(SCM) $0.9 \%(w / v) ~ \mathrm{NaCl}$, $0.1 \%(\mathrm{v} / \mathrm{v})$ formaldehyde, $0.1 \%$ (w/v) PEG and $10 \mathrm{mM}$ ethylenediaminetetraacetic acid in $\mathrm{H}_{2} \mathrm{O}$ ] was used for counting of sperm cells. Calcium ionophore A23187 (free acid; CalbiochemNovabiochem Corp., San Diago, USA) was prepared at $100 \mathrm{mM}$ in DMSO, and frozen stored at $-30{ }^{\circ} \mathrm{C}$ in small aliquots wrapped from light. Immediately before use, an aliquot was thawed and used at a 1:100 dilution in saline medium to give a final concentration of $1 \mathrm{mM}$.

\section{Semen collection}

Ejaculates were collected from well-trained buffalo-bulls using an artificial vagina of inner sleeve temperature $40{ }^{\circ} \mathrm{C}$ according to Rasul et al. (19). Ejaculates were collected twice a week early morning with $10 \mathrm{~min}$ interval. Immediately, after collection the collected ejaculates were kept in water bath of $37{ }^{\circ} \mathrm{C}$ during initial semen evaluation.

\section{Semen evaluation}

As soon as possible the collected ejaculates were observed for color, consistency, hygienic quality and volume. An aliquot $(200 \mu \mathrm{L})$ from each ejaculate was used for evaluation of the following sperm characteristics:

\section{Sperm motility \\ 1.1. Mass motility}

As quick as possible the fresh semen samples were examined on pre-warmed glass slide on a warm stage $\left(38.5^{\circ} \mathrm{C}\right)$ under phase contrast microscope (Olympus BX20, Tokyo, Japan) at $100 \times$ magnification. The mass motility was scored from 0-5 grade depending upon the speed and intensity of waves. All ejaculates of mass motility less than 3 were excluded.

\subsection{Individual motility}

An aliquot $(5 \mu \mathrm{L})$ of fresh semen was placed on warm glass slide and diluted with $20 \mu \mathrm{L}$ isotonic sodium citrate dihydrate $2.9 \%$. The diluted semen was covered with a warm cover slip and examined under phase contrast microscope at 200 and $400 \times$ magnifications. At least, five microscopic fields were examined to calculate the average in increments of $5 \%$. Ejaculates of less than $70 \%$ progressive motility were excluded.

\section{Sperm viability}

Alive sperm percentage was determined in Eosin-Nigrosin (EN) stained semen smear according to Bjoerndahl et al. (20). Briefly, $5 \mu \mathrm{L}$ of fresh semen was mixed with $20 \mu \mathrm{L}$ pre warmed EN stain and smeared on warm glass 
slide, dried and examined at 400 and $1000 \times$ magnification of phase contrast microscope. At least, two microscopic fields containing 200 spermatozoa were examined. The proportion of unstained spermatozoa was expressed as viability\%.

\section{Sperm cell concentration}

Sperm cell concentration was determined by direct cell count using Neubauer haemocytometer (Marienfeld, Germany) (21). Exactly, 10 $\mu \mathrm{L}$ of fresh semen was diluted with $3000 \mu \mathrm{L}$ SCM and thoroughly mixed. An aliquot (12.5 $\mu \mathrm{L})$ of sperm suspension was spotted into counting chamber and count sperm cells under phase contrast microscope at $400 \times$ magnification.

\section{Semen dilution and cryopreservation}

Immediately before dilution, Tris-based extender was centrifuged at $3310 \mathrm{x}$ g for $20 \mathrm{~min}$ and the upper portion of supernatant and sediment were discarded (22). Extenders (intermediate portion after centrifugation) were prepared one day before semen collection and kept overnight at $4{ }^{\circ} \mathrm{C}$. The ejaculates of at least 3 score mass motility, $70 \%$ progressive motility and $800 \times 10^{6} / \mathrm{mL}$ sperm cell concentration were diluted. Both, ejaculate and extender were maintained in water bath of $37^{\circ} \mathrm{C}$. The selected ejaculates were pooled together to avoid the bull effect before being diluted with cryoprotectant free extender stepwise at room temperature. The semen was diluted gradually 1:10 (each straw had at least $20 \times 10^{6}$ motile sperm). Diluted semen was cooled to $4{ }^{\circ} \mathrm{C}$ for $2 \mathrm{~h}$ and further diluted (1:1) with cryoprotectant containing extender (23). The cryoprotectant was either $7 \%$ GLY (24) or 5\% EG (3) or 5\% DMSO (19). Diluted semen was equilibrated at $4{ }^{\circ} \mathrm{C}$ for at least $4 \mathrm{~h} \mathrm{(25)}$ before being loaded in $0.5 \mathrm{~mL}$ polyvinyl French straws (IMV, France) with a suction pump at $4{ }^{\circ} \mathrm{C}$ in a cold cabinet (Minitub, Germany). The filled straws were plunged above liquid nitrogen vapor $\left(-120^{\circ} \mathrm{C}\right)$ for at least $10 \mathrm{~min}$ then immersed in liquid nitrogen $\left(-196^{\circ} \mathrm{C}\right)$ for storage.

\section{Evaluation of frozen-thawed semen}

Two straws for each treatment were thawed in water bath of $39^{\circ} \mathrm{C}$ for exactly $1 \mathrm{~min}$, thoroughly dried and gently evacuated in $1.5 \mathrm{~mL}$ vial which kept on a warming plate $\left(38.5^{\circ} \mathrm{C}\right)$ during evaluation. Frozen-thawed semen was examined for the following sperm characteristics:

\section{Progressive motility}

The proportion of progressive motility was determined in wet mount using $10 \mu \mathrm{L}$ of frozenthawed semen on pre-warmed glass slide covered with warm cover slip (18 x $18 \mathrm{~mm})$, and examined at $400 \times$ magnification under phase contrast microscope. Five microscopic fields were examined for the proportion of progressive motile sperm according to Chutia et al. (26).

\section{Sperm viability}

The proportion of live sperms was determined in EN-stained smears similarly as mentioned before in fresh semen analysis. At least, 200 spermatozoa were examined for each semen sample to calculate the proportion of unstained spermatozoa which expressed as viability $\%$.

\section{Sperm plasma membrane integrity}

Plasma membrane integrity was determined by using hypo-osmotic swelling test (HOST) (27). Hypo osmotic solution was prepared by dissolving $0.73 \mathrm{~g}$ sodium citrate and $1.35 \mathrm{~g}$ fructose in $100 \mathrm{~mL}$ Milli-Q water (osmotic pressure $\sim 190 \mathrm{mOsmol} / \mathrm{kg}$ ). For evaluation, 50 $\mu \mathrm{L}$ of frozen-thawed semen was suspended in $500 \mu \mathrm{L}$ of pre-warmed HOST solution and incubated at $37^{\circ} \mathrm{C}$ for $30-60 \mathrm{~min}$. After incubation, $50 \mu \mathrm{L}$ of HOST exposed sperm suspension was fixed with an equal volume of $2 \%$ Glutaraldehyde in sodium cacodylate buffer for at least $30 \mathrm{~min}$ at room temperature. Two wet mount $(2 \mu \mathrm{L} /$ each $)$ were prepared and examined for the proportion of sperm cells showing tail swelling under $(1000 \times)$ phase contrast microscope. In total, 200 spermatozoa per each wet mount were examined for their swelling characterized by coiled tail. The proportion of HOST-positive sperm cells (\% intact-membrane) was determined from the following equation (HOST-positive $\%=\mathrm{Y}-\mathrm{X} / 400 \times$ 
$100)$, where $X$ was spermatozoa having tail abnormalities and $\mathrm{Y}$ was spermatozoa having swelled tails according to Fukui et al. (28).

4. Acrosomal membrane integrity

Acrosomal membrane integrity was determined in EN-stained semen smears according to the method described by Bamba [29]. At least, 200 spermatozoa were examined in each semen sample under phase contrast microscope at $1000 \times$ magnification. Sperm cells having crescent shape apical ridge considered intactacrosome otherwise consider damaged-acrosome.

5. Stimulation of frozen-thawed spermatozoa with $\mathrm{Ca}^{2+}$ and $\mathrm{Ca}^{2+}$ ionophore A23187

Spermatozoa were incubated with $\mathrm{Ca}^{2+}$ and $\mathrm{Ca}^{2+}$ ionophore A23187 as previously described by Almadaly et al. (18). Two straws were thawed at $39{ }^{\circ} \mathrm{C}$ for $1 \mathrm{~min}$ and evacuated in $1.5 \mathrm{~mL}$ vials. The two vials were centrifuged at $830 \mathrm{x} \mathrm{g}$ for $6 \mathrm{~min}$ at room temperature and remove the supernatant. The sperm pellets were resuspended in saline medium then was overlay on sucrose medium containing $0.1 \%$ PVA and $0.1 \%$ PEG and centrifuged at $400 \mathrm{x} \mathrm{g}$ for $5 \mathrm{~min}$ then at $1000 \mathrm{x} \mathrm{g}$ for $10 \mathrm{~min}$ at room temperature. After centrifugation the supernatant was discarded and sperm cell concentration was adjusted to $6 \times 10^{6} / \mathrm{mL}$. Spermatozoa were resuspended in saline medium containing $3 \mathrm{mM}$ $\mathrm{CaCl}_{2}$ and incubated in the presence and absence (DMSO vehicle, control) of $1 \mathrm{mM} \mathrm{Ca}^{2+}$ ionophore A23187 at $37^{\circ} \mathrm{C}$ for up to $60 \mathrm{~min}$ in air. At $0,5,10,15,30$, and 60 min subsamples were collected and fixed with $1 \%$ Glutaraldehyde in $0.165 \mathrm{M}$ cacodylate buffer at room temperature for at least $30 \mathrm{~min}$. After incubation, wet mounts $(2 \mu \mathrm{L} /$ each $)$ were prepared and examined under oil immersion lens of phase contrast microscope.

Sperm having a clear, dense apical ridge on the head were considered acrosome-intact, but sperm cells with ruffled or vesiculated acrosome or without acrosome were considered acrosome reacted. The raw data expressed as \% acrosome reaction (AR) was transformed to percentage of spermatozoa that were acrosome- intact at the onset of stimulation but subsequently have an $\mathrm{AR}$ in response to $\mathrm{Ca}^{2+}$ and $\mathrm{Ca}^{2+} \mathrm{A} 23187$ (\% relative AR) with the following formula: (\%AR at each time point of stimulation - percentage at $0 \mathrm{~min}) /(100$ - percentage at $0 \mathrm{~min}) \times 100(30)$.

\section{Estrus synchronization and artificial insem-} ination

This experiment was applied on 75 pluriparous buffalo-cows maintained at the same farm of buffalo-bulls and of more than 90 days postpartum with normal genitalia. Before the onset of experiment all buffalo-cows were examined by rectal palpation and/or ultrasound (Mindry, Germany) for judging the ovarian activity which indicated by the presence of follicles and/or corpus luteum. Cyclic buffalo-cows received double dose of prostaglandin $F_{2 \alpha}$ $\left(\mathrm{PGF}_{2 \alpha}\right)$ with 11 days interval (31) where each animal received 750 pg $\mathrm{PGF}_{2 \alpha}$ analogue (Cloprostenol sodium, Estrumate, Berkhamsted, England) intramuscularly on days 0 and 11 . Exactly, $48 \mathrm{~h}$ after the second dose of $\mathrm{PGF}_{2 \alpha}$ animals were carefully observed for the signs and/or the reflexes of estrus throughout the day and night. Estrus buffalo-cows were inseminated with frozen-thawed straws (two straws/animal) containing either GLY $(n=25)$ or EG $(n=25)$ or DMSO $(n=25)$. All animals were intrauterine inseminated (recto-vaginal technique) by the same inseminator using ampm regime.

\section{Pregnancy diagnosis}

All inseminated buffalo-cows were rectally palpated and/or ultrasound examined for positive findings of pregnancy on day 45 post-insemination. Presence of either amniotic vesicle or fetal membrane slip was considered a reliable sign for the pregnant buffalo-cow.

\section{Statistical analysis}

The results were presented as mean \pm standard error of mean (SEM). All analyses were achieved using a statistical software program (Graphpad Prism Version 6.0; Graphpad Software, San Diego, CA, USA). Analysis of variance (ANOVA) with Turkey's multiple com- 
parison test was used subsequently for comparison of means at a significance level of $p<0.05$ (32). The proportion of pregnant females was analyzed by Chi-square test at $p<0.05$.

\section{Results}

Sperm characteristics of fresh semen

The obtained results revealed that all ejaculates of the five buffalo-bulls used for processing of frozen semen had acceptable mass motility (4.5 \pm 0.2$)$, progressive motility (78.7 $\pm 1.3)$, viability $(79.5 \pm 0.8)$ and sperm cell concentration $\left(1.6 \pm 0.1 \times 10^{6} / \mathrm{mL}\right)$ as well as $\%$ abnormal morphology $(9.6 \pm 0.7$, Table 1$)$.

Sperm characteristics of frozen-thawed semen

\section{Sperm motility}

The mean \pm SEM of $\%$ progressive motility of frozen-thawed buffalo-bull spermatozoa frozen-stored in the presence of one of the three cryoprotectants have been presented in Table 2. The progressive motility were extremely $(p<$ $0.001)$ different among the three cryoprotectant where it was greater in GLY $(41.3 \pm 1.2)$ followed by EG $(31.4 \pm 0.9)$ and lower $(25.4 \pm 1.1)$ for DMSO.

\section{Sperm viability}

Regarding the results of sperm viability (Table 2), GLY yielded the greater $(p<0.001)$ sperm viability $(47.7 \pm 1.1)$ than both EG (42.3 $\pm 0.8)$ and DMSO (39.2 \pm 1.2$)$ without significant difference between EG and DMSO.

\section{Plasma membrane integrity}

The proportion of intact-plasma membrane of spermatozoa frozen-stored in the presence of GLY or EG (Table 2) were greater $(p<0.001)$ than that of DMSO $(46.3 \pm 0.9)$ without significant difference between GLY $(58.4 \pm 1.5)$ and $\mathrm{EG}(58.7 \pm 0.8)$.

\section{Acrosomal membrane integrity}

The proportion of intact-acrosome was significantly $(p<0.001)$ different among the three cryoprotectant with greater $\%(61.7 \pm 1.2)$ in GLY than EG (58.4 \pm 0.8$)$ and DMSO (48.4 \pm $0.5)$ as shown in Table 2.
5. Induction of $\mathrm{AR}$ with $\mathrm{Ca}^{2+}$ and $\mathrm{Ca}^{2+}$ ionophore A23187

Incubation of spermatozoa with $\mathrm{Ca}^{2+}$ / A23187 resulted in a time-dependent increase in the \% AR (Table 3), in the three cryoprotectants without significant $(p \geq 0.05)$ difference at 0 and 5 min but with significant $(p<0.01)$ difference at 10, 15, 30 and 60 min. Regarding \% relative AR (Table 4) it was similar among the three cryoprotectants at 5,10 and 15 min but was extremely different among them at 30 and $60 \mathrm{~min}$. Almost in all incubation times GLY was predominant in both $\% \mathrm{AR}$ and $\%$ relative AR (Tables 3, 4).

\section{Pregnancy rate}

The pregnancy rate was different $\left(x^{2}=7.32\right.$, $p<0.05)$ among the three cryoprotectants as depicted in Figure 1, where it was greater $(52 \%)$ with GLY than EG (32\%) and DMSO (16\%).

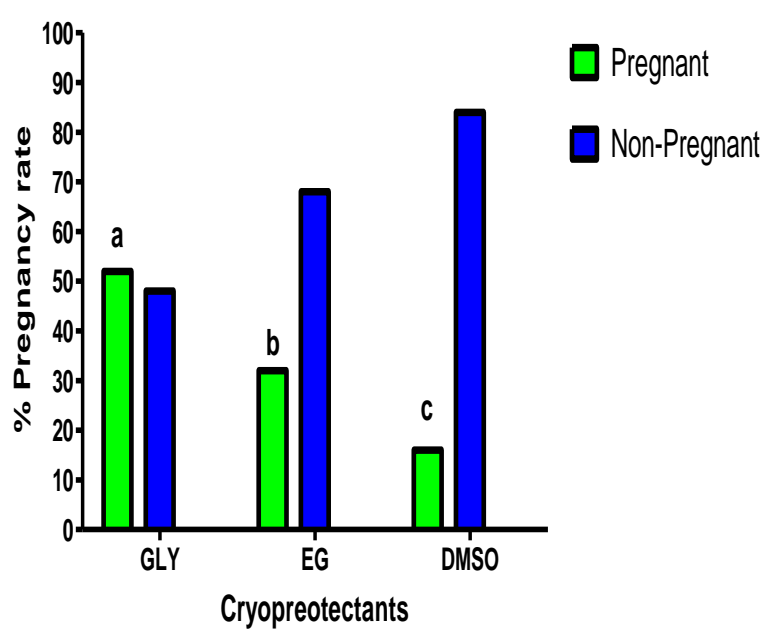

\section{Chi-square $=7.32 \quad P=0.025$}

Figure 1: Effect of GLY, EG and DMSO in Trisbased extender on the in vivo fertility of frozenthawed buffalo bull spermatozoa

GLY = Glycerol, EG = Ethylene glycol, DMSO = Dimethyl sulfoxide. 
Table 1: Fresh semen quality (mean \pm SEM) of buffalo-bulls*

\begin{tabular}{cccccc}
\hline $\begin{array}{c}\text { No. of } \\
\text { replicates }\end{array}$ & $\begin{array}{c}\text { Mass motility } \\
(0-5)\end{array}$ & $\begin{array}{c}\text { Progressive } \\
\text { motility }(\%)\end{array}$ & $\begin{array}{c}\text { Sperm } \\
\text { viability (\%) }\end{array}$ & $\begin{array}{c}\text { Abnormal } \\
\text { morphology }(\%)\end{array}$ & $\begin{array}{c}\text { Sperm cell concentration } \\
(\mathrm{x} \mathrm{10} / \mathrm{mL})\end{array}$ \\
\hline 12 & $4.5 \pm 0.2$ & $78.7 \pm 1.3$ & $79.5 \pm 0.8$ & $9.6 \pm 0.7$ & $1.6 \pm 0.1$ \\
\hline
\end{tabular}

*For each replicate ejaculates were collected and examined in duplicate for each semen parameter.

Table 2: Characteristics (mean \pm SEM) of frozen-thawed buffalo-bull spermatozoa frozen-stored with different cryoprotectants*

\begin{tabular}{cccccc}
\hline Cryoprotectant & $\begin{array}{c}\text { No. of } \\
\text { replicates }\end{array}$ & $\begin{array}{c}\text { Progressive } \\
\text { motility } \\
(\%)\end{array}$ & $\begin{array}{c}\text { Viability } \\
(\%)\end{array}$ & $\begin{array}{c}\text { Plasma } \\
\text { membrane integrity } \\
(\%)\end{array}$ & $\begin{array}{c}\text { Acrosomal } \\
\text { membrane integrity } \\
(\%)\end{array}$ \\
\hline GLY & 17 & $41.3 \pm 1.2^{\mathrm{a}}$ & $47.7 \pm 1.1^{\mathrm{a}}$ & $58.4 \pm 1.5^{\mathrm{a}}$ & $61.7 \pm 1.2^{\mathrm{a}}$ \\
\hline EG & 17 & $31.4 \pm 0.9^{\mathrm{b}}$ & $42.3 \pm 0.8^{\mathrm{b}}$ & $58.7 \pm 0.8^{\mathrm{a}}$ & $58.4 \pm 0.8^{\mathrm{b}}$ \\
\hline DMSO & 17 & $25.4 \pm 1.1^{\mathrm{c}}$ & $39.3 \pm 1.2^{\mathrm{b}}$ & $46.3 \pm 0.9^{\mathrm{b}}$ & $48.4 \pm 0.5^{\mathrm{c}}$ \\
\hline P value & - & $<0.001$ & $<0.001$ & $<0.001$ & $<0.001$
\end{tabular}

*Two straws were thawed and pooled together for each replicate and examined in duplicate for each sperm characteristic. Means bearing different superscript within the same column were significantly different at $p<0.05$.

Table 3: The $\%$ AR (mean \pm SEM) of frozen-thawed buffalo-bull spermatozoa frozen-stored with different cryoprotectants in response to $\mathrm{Ca}^{2+}$ and $\mathrm{Ca}^{2+}$ ionophore $\mathrm{A} 23187 *$

\begin{tabular}{cccccccc}
\hline \multirow{2}{*}{ Cryoprotectant } & \multirow{2}{*}{$\begin{array}{c}\text { No. of } \\
\text { replicates }\end{array}$} & \multicolumn{6}{c}{ Incubation time (min) } \\
\cline { 3 - 8 } & 6 & 5 & 10 & 15 & 30 & 60 \\
\hline GLY & 6 & $21.2 \pm 0.7^{\mathrm{a}}$ & $28.8 \pm 0.6^{\mathrm{a}}$ & $36.2 \pm 1.2^{\mathrm{a}}$ & $46.0 \pm 1.3^{\mathrm{a}}$ & $62.7 \pm 1.4^{\mathrm{a}}$ & $76.3 \pm 1.1^{\mathrm{a}}$ \\
\hline EG & 6 & $19.3 \pm 0.6^{\mathrm{a}}$ & $30.2 \pm 0.8^{\mathrm{a}}$ & $33.7 \pm 0.8^{\mathrm{ab}}$ & $42.5 \pm 0.8^{\mathrm{ab}}$ & $52.2 \pm 1.1^{\mathrm{b}}$ & $66.7 \pm 1.5^{\mathrm{b}}$ \\
\hline DMSO & 6 & $19.2 \pm 0.5^{\mathrm{a}}$ & $28.3 \pm 0.7^{\mathrm{a}}$ & $31.7 \pm 0.7^{\mathrm{b}}$ & $41.5 \pm 0.8^{\mathrm{b}}$ & $47.5 \pm 0.8^{\mathrm{c}}$ & $59.2 \pm 0.8^{\mathrm{c}}$ \\
\hline P value & - & 0.06 & 0.13 & 0.008 & 0.01 & $<0.001$ & $<0.001$
\end{tabular}

*Two straws were thawed and pooled together for each replicate and examined for the \% AR in response to calcium ionophore. Values bearing one similar superscript within the same time point were similar $(p \geq 0.05$, repeated measures ANOVA followed by Tukey's multiple comparison test).

Table 4: The \% relative AR (mean \pm SEM) of frozen-thawed buffalo-bull spermatozoa frozen-stored with different cryoprotectants in response to $\mathrm{Ca}^{2+}$ and $\mathrm{Ca}^{2+}$ ionophore A23187*

\begin{tabular}{ccccccc}
\hline \multirow{2}{*}{ Cryoprotectant } & \multirow{2}{*}{$\begin{array}{c}\text { No. of } \\
\text { replicates }\end{array}$} & 5 & 10 & 15 & 30 & 60 \\
\cline { 3 - 7 } & 6 & $10.0 \pm 0.7^{\mathrm{a}}$ & $20.0 \pm 2.1^{\mathrm{a}}$ & $31.4 \pm 1.9^{\mathrm{a}}$ & $52.6 \pm 2.0^{\mathrm{a}}$ & $72.1 \pm 1.5^{\mathrm{a}}$ \\
\hline GLY & 6 & $13.4 \pm 1.4^{\mathrm{a}}$ & $17.7 \pm 1.0^{\mathrm{a}}$ & $28.7 \pm 0.9^{\mathrm{a}}$ & $40.6 \pm 1.4^{\mathrm{b}}$ & $58.6 \pm 1.9^{\mathrm{b}}$ \\
\hline EG & 6 & $11.2 \pm 1.3^{\mathrm{a}}$ & $16.2 \pm 1.0^{\mathrm{a}}$ & $27.6 \pm 1.3^{\mathrm{a}}$ & $34.9 \pm 1.1^{\mathrm{b}}$ & $49.5 \pm 1.0^{\mathrm{c}}$ \\
\hline DMSO & - & 0.06 & 0.16 & 0.17 & $<0.001$ & $<0.001$ \\
\hline P value & & &
\end{tabular}




\section{Discussion}

It is imperative to mention that buffalo-bull sperm are more susceptible to freeze-thaw damage than other domestic animals. This poor freezability of buffalo-bull sperm might be related to the lower content of membrane phospholipid and/or its loss during freezing and thawing procedures (33). Also, intracellular ice crystal formation during cryopreservation was the main cause of sperm cell damage. Thus, the composition of diluent containing proper cryoprotectants is critical factor for successful semen preservation (34) as the cryoprotectant minimizes intracellular ice formation (12). Moreover, the ideal cryoprotectant must have low molecular weight, high water solubility, permeated cell quickly and of low toxicity (35).

On the basis of existing information on freezing of buffalo-bull sperm in the presence of different cryoprotectants, GLY improved the post-thaw sperm characteristics including motility, viability, plasma membrane integrity, acrosomal membrane integrity, \% AR and \% relative $\mathrm{AR}$ in response to calcium ionophore A23187 as well as yielded higher pregnancy rate in comparison with EG and DMSO. These findings were regular with the findings of Tasdemir et al. (34) who reported that there was no advantage in using EG or DMSO spermatozoa where GLY yielded the best post-thaw sperm characteristics in comparison with EG and DMSO. Also, Guerrero (36) found that the post-thaw progressive motility and \% intactmembrane of bull sperm frozen in 7\% GLYTris-based extender were significantly higher than those of sperm frozen in 7\% EG-Trisbased extender. On contrary, \% intact-acrosome was similar between $7 \%$ GLY and 7\% EG.

Moreover, the findings of this study were in harmony with Rasul et al. (19) who concluded that GLY is still an efficient cryoprotectant for buffalo-bull sperm and DMSO antagonized the action of GLY and thus reduced the post-thaw quality of buffalo-bull sperm. Moreover, 6\% GLY added at $37{ }^{\circ} \mathrm{C}$, provided better cryoprotection to the motility and plasma membrane integrity of buffalo-bull sperm (19).
Our findings were in agreement with Rohilla et al. (25) who reported that $6.8 \%$ GLY greatly improve post-thaw buffalo-bull sperm motility, viability, and intact-acrosome in comparison with 5\% EG. Furthermore, Gabr (37) reported that higher concentration of cryoprotectant for instance, $>7 \%$ GLY resulted in gradual reduction in motility. Post-thaw sperm motility with GLY and DMSO didn't differ significantly and there is a beneficial effect of 7\% GLY on improving sperm motility of buffalo-bull semen extended in Tris-based extender in comparison with different $(5,7,10 \%)$ concentrations of DMSO and EG (37).

Noteworthy, our findings were partially inconsistent with the findings of Swelum et al. (3) who reported that $5 \% \mathrm{EG}$ resulted in greater post-thaw intact-acrosome, intact-plasma membrane and conception rate of buffalo-bull spermatozoa than 7\% GLY. On contrary, the postthaw sperm motility was lower with $5 \%$ EG than $7 \%$ GLY which was in agreement with our results but sperm viability didn't affected with the different cryoprotectants either GLY or EG. El-Harairy et al. (38) found that post-thaw motility and the conception rate of bull spermatozoa frozen in lactose-yolk-citrate extender containing $7 \%$ GLY or $7 \%$ DMSO was similar. This discrepancy might be due to different animal species, breed, and semen extender as well as different cooling and freezing protocols. For instance, permeability of sperm plasma membrane to cryoprotectant and the consequent osmotic damage was species-dependent because each animal species has different structure and composition of sperm plasma membrane.

It is well known that the sperm plasma membrane considered being the foremost site of freeze-thaw damage due to its high content of poly unsaturated fatty acids that render it more vulnerable to the intracellular ice crystals formed during the freezing process. This membrane damage lead to loss of lipids and phospholipids (39), cholesterol and consequently, the ratio of poly unsaturated fatty acids and saturated fatty acids is disturbed. On the basis of results obtained in the present study that GLY provide higher proportion of intact-plasma membrane, $\% \mathrm{AR}$ and $\%$ relative AR post-thaw 
thus, GLY have utmost cryoprotective effect on buffalo-bull sperm plasma membrane in comparison with EG and DMSO.

Incorporation of GLY in semen diluent used for frozen storage of buffalo-bull semen significantly improved its post-thaw quality and function than both EG and DMSO might be due to EG has toxic effect on sperm cells where it badly affects the motility of fresh and frozenthawed semen (40). Furthermore, EG could not reverse the capacitation like changes (cryocapcitation) of frozen-thawed sperm cells (41) which might be the plausible explanation for the improved function (in terms of $\% \mathrm{AR}$ and $\%$ relative $\mathrm{AR}$ ) of sperm cells frozen in the presence of GLY compared to those frozen in the presence of EG.

Since the true test to evaluate a semen sample is to estimate the fertility rate after its in vivo insemination in a routine AI program under field conditions (42). Then GLY was efficient in cryopreservation of buffalo-bull sperm as the higher in vivo fertility was recorded with extender having 7\% GLY compared to 5\% EG and 5\% DMSO. This high fertility is a logical result for the improved sperm characteristics viz; progressive motility, plasma and acrosomal membranes integrity, viability, \% AR and \% relative AR suggesting that all the sperm characteristics used to assess the semen quality do have substantial role in the fertilization process (43). In conclusion, incorporation of 7\% GLY in the semen extender significantly improves in vitro quality and in vivo fertility of buffalo-bull semen.

\section{Conflict of interest}

All the authors declare no conflict of interest.

\section{Acknowledgments}

The authors thank all staff members of Mehalet-Mousa Research Station, and to staff of International Livestock Management training center, Sakha, Kafrelsheikh, Egypt for their great assistance during collection and processing of semen.

\section{References}

1. Food and Agricultural Organization (FAO). FAOSTAT, Global livestock production and health atlas. Animal Production and Health Division, Roma, Italy, 2018. Available from http://www.fao.org/faostat/en/\#data.

2. Andrabi SMH. Factors affecting the quality of cryopreserved buffalo (Bubalus bubalis) bull spermatozoa. Reprod Domest Anim 2009; 44: 552-69.

3. Swelum AA, Mansour HA, Elsayed AA, Amer HA. Comparing ethylene glycol with glycerol for cryopreservation of buffalo bull semen in eggyolk containing extenders. Theriogenology 2011; 76: 833-42.

4. Singh P, Kumar D, Kumar P, Singh I, Yadav PS. Cryopreservation and quality assessment of buffalo bull semen collected from farmer's doorstep. Agri Res 2013; 2: 148-52.

5. Lei SU, Xilong LI, Jiexia Quan SY, Yahui LI, Xiechao HEX, Ianghui T. A comparison of the protective action of added egg yolks from five avian species to the cryopreservation of bull sperm. Anim Reprod Sci 2007; 104: 212-9.

6. Watson PF. The causes of reduced fertility with cryopreserved semen. Anim Reprod Sci 2000; 60-61: 481-92.

7. Mazur P. Freezing of living cells: mechanisms and implications. Am J Physiol 1984; 247: 125-42.

8. Ansari MS, Rakha BA, Andrabi SMH, Ullah N, Iqbal R, Holt WV, Akhter S. Glutathione supplemented tris-citric acid extender improves the postthaw quality and in vivo fertility of buffalo (Bubalus bubalis) bull spermatozoa. Reprod Biol 2012; 12 : 271-6.

9. Chohan KR, Iqbal J, Asghar AA, Chaudhry MA. Fertility of liquid and frozen semen in Nili Ravi buffaloes. Pak Vet J 1992; 12: 4-5.

10. Pandey AK, Dhaliwal GS, Ghuman SPS, Agarwal SK. Impact of pre-ovulatory follicle diameter on plasma estradiol, subsequent luteal profiles and conception rate in buffalo (Bubalus bubalis). Anim Reprod Sci 2011; 123: 169-74.

11. Watson PF. The roles of lipid and protein in the protection of ram spermatozoa at $5{ }^{\circ} \mathrm{C}$ by eggyolk lipoprotein. J Reprod Fertil 1981; 62: 483-92.

12. Hammerstedt RH, Graham JK, Nolan john P. Cryopreservation of mammalian sperm: what we ask them to survive. J Androl 1990; 11: 73-88.

13. Holt WV. Basic aspects of frozen storage of semen. Anim Reprod Sci 2000; 62: 3-22.

14. Gao DY, Mazur P, Critser JK. Fundamental cryobiology of mammalian spermatozoa. In: Karow AM, Critser JK eds. Reproductive Tissue Banking. 
Scientific Principles. San Diego: Academic Press, 1997, 263-328.

15. Wündrich K, Paasch U, Leicht M, Glander HJ. Activation of caspases in human spermatozoa during cryopreservation - an immunoblot study. Cell Tissue Bank 2006; 7: 81-90.

16. Guthrie HD, Liu J, Critser JK. Osmotic tolerance limits and effects of cryoprotectants on motility of bovine spermatozoa. Biol Reprod 2002; 67: 1811-6.

17. Ball BA, Vo A. Osmotic tolerance of equine spermatozoa and the effects of soluble cryoprotectants on equine sperm motility, viability, and mitochondrial membrane potential. J Androl 2001; 22: 1061-9.

18. Almadaly E, Hoshino Y, Ueta T, Mukoujima K, Shukry M, Farrag F, El-Kon I, Kita K, Murase T. Desalted and lyophilized bovine seminal plasma delays induction of the acrosome reaction in frozenthawed bovine spermatozoa in response to calcium ionophore. Theriogenology 2015; 83: 175-85.

19. Rasul Z, Ahmed N, Anzar M. Antagonist effect of DMSO on the cryoprotection ability of glycerol during cryopreservation of buffalo sperm. Theriogenology 2007; 68: 813-9.

20. Bjoerndahl L, Soederlund I, Kvist U. Evaluation of the one-step eosin-nigrosin staining technique for human sperm vitality assessment. Hum Reprod 2003; 18: 813-6.

21. Graham, JK. Analysis of stallion semen and its relation to fertility. Vet Clin North Am Equine Pract 1996; 12: 119-29.

22. Gil J, Soderquist L, Rodriguez-Martinez H. Influence of centrifugation and different extenders on post-thaw sperm quality of ram semen. Theriogenology 2000; 54: 93-108.

23. Masuda H. Preservation of semen in liquid and frozen state, In: Artificial Insemination Association of Japan (Eds.), Textbook for the Course of Artificial Insemination in Domestic Animals., Fuji Planning. 2006, 343-52.

24. Abbas A, Andrabi MSH. Effect of different glycerol concentrations on motility before and after freezing, recovery rate, longevity and plasma membrane integrity of Nili Ravi buffalo bull spermatozoa. Pak Vet J 2002; 22: 1-4.

25. Rohilla RK, Tuli RK, Goyal RL. Comparative study of the effects of cryoprotective agents in freezing Murrah buffalo bull semen. Ind J Vet Res 2005; 14: 37-43.

26. Chutia T, Biswas RK, Tamuli MK, Deka BC, Sinha S, Goswami J, Banik S, Kayastha RB. Effect of holding of semen and washing of seminal plasma on quality and fertility of Hampshire boar semen preserved at liquid state. Anim Reprod Sci 2014; 45: 141-9.

27. Waheed S, Ahmad N, Rahman NU, Jamilur-Rahman H, Younis M, Iqbal S. Evaluation of duck egg yolk for the cryopreservation of Nili-Ravi buffalo bull semen. Anim Reprod Sci 2012; 131: 95-9.

28. Fukui Y, Togawa M, Abe N, Takano Y, Asada M, Okada A, Iida K, Ishikawa H, Ohsumi S. Validation of the sperm quality analyzer and the hypo-osmotic swelling test for frozen-thawed ram and minke whale (Balanenoptera bonarensis) spermatozoa. J Reprod Dev 2004; 50: 147-54.

29. Bamba K. Evaluation of acrosomal integrity of boar spermatozoa by bright field microscopy using an eosine-nigrosine stain. Theriogenology 1988; 29: $1245-51$.

30. Murase T, Mukohjima K, Sakaguchi S, Ohtani T, Tsubota T, Kita I. Characterization of frozen-thawed Japanese black bull spermatozoa by standard semen analysis, mucus penetration test and the ability to undergo the acrosome reaction in response to calcium and the calcium ionophore A23187. J Reprod Dev 2001; 47: 237-43.

31. Barile VL. Technologies related with the artificial insemination in Buffalo. J Buffalo Sci 2012; 1: 139-46.

32. Snedecor, GW, Cochran, WG. Statistical Methods, $9^{\text {th }}$ edition. Iowa State University Press Ames, Iowa, United States 1994.

33. Galli A, Bornaghi V, Balduzzi D, Buttazzoni L, Aleandri R. Sexual behavior and semen quality relating to italian buffalo. Proc $3^{\text {rd }}$ World Buffalo Congr, Varna, Bulgaria 1993; 1: 562-70.

34. Tasdemir U, Buyukleblebici S, Tuncer PB, Coskun E, Ozgurtas T, Aydın FN, Buyukleblebici $\mathrm{O}$, Gurcan IS. Effects of various cryoprotectants on bull sperm quality, DNA integrity and oxidative stress parameters. Cryobiology 2013; 66: 38-42.

35. Harrison RAP, Ashworth PJC, Miller NGA. Assessment of sperm function under fertilizing conditions. Reprod Dom Anim 1996; 31: 25-30.

36. Guerrero CA. Cryopreservation and intracytoplasmic sperm injection with bovine epididymal spermatozoa (PhD Thesis). Fac Agric and Mechanical College, Louisiana State University; Mexico, 2006.

37. Gabr AA. Assessment of in vitro and in vivo fertilizing capacity of buffalo sperm treated with various cryoprotectants ( $\mathrm{PhD}$ Thesis). Fac Agric, Mansoura University, Egypt, 2009.

38. El-Harairy MA, Eid LN, Zeidan AEB, Abd El-Salaam AM, El-Kishk MAM. Quality and fertility of the frozen-thawed bull semen as affected by 
the different cryoprotectants and glutathione levels. J Am Sci 2011; 7: 791-801.

39. Sarmah BC, Kaker ML, Razdan MN. Effect of cold shock and freezing on loss of total lipids and phospholipids of buffalo spermatozoa (Bubalus bubalis). Theriogenology 1984; 22: 621-4.

40. Alvarez JG, Storey BT. Taurine, hypotaurine, epinephrine and albumin inhibit lipid peroxidation in rabbit spermatozoa. Biol Reprod 1983; 29: 548-55.

41. Rota A, Milani C, Cabianca G, Martini M.
Comparison between glycerol and ethylene glycol for dog semen cryopreservation. Theriogenology 2006; 65: 1848-58.

42. Ansari MS, Rakha BA, Akhter S. Cryopreservation of Nili-Ravi buffalo (Bubalus bubalis) se-

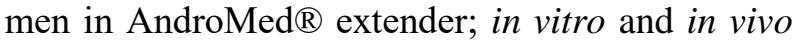
evaluation. Reprod Dom Anim 2017; 52: 992-7.

43. Layek SS, Mohanty TK, Kumaresan A, Parks JE. Cryopreservation of bull semen: Evolution from egg yolk based to soybean based extenders. Anim Reprod Sci 2016; 172:1-9. 